Сливинский А. А., Нетяга А. В.

Национальный технический университет Украины «Киевский политехнический институт имени Игоря Сикорского». Украина, г. Киев

\title{
ВЛИЯНИЕ НАНОРАЗМЕРНЫХ ИНОКУЛЯНТОВ НА СТРУКТУРУ И СВОЙСТВА МЕТАЛЛА ШВА, ВЫПОЛНЕННОГО ПРОВОЛОКОЙ АУСТЕНИТНОГО КЛАССА
}

Подтверждена возможность качественного влияния наноразмерных иастии, различных компонентов, введенных в зону сварки при электродуговой механизированной сварке в смеси газов, на твердость металла шва и измельчение его структуры. На основе этого предложено использование нанокомпонентов с содержанием $\mathrm{TiO}_{2}, \mathrm{SiO}_{2}$ и $\mathrm{TiC}$ при электродуговой механизированной сварке в смеси газов среднелегированных мартенситно-бейнитных сталей высоколегированной проволокой аустенитного класса. Проведены лабораторные, расчетные и металлографические исследования по твердости и измельчению структуры наплавленного металла, которые показали адекватность предложенного метода. [dx.doi.org/10.29010/080.6]

Ключевые слова: механизированная сварка в смеси газов; наночастицы; нанопорошок; наноинокулянты; нанокомпоненты; наноразмерные инокулянты; высокопрочная среднелегированная мартенситно-бейнитная сталь; аустенитная проволока; микротвердость; металлография.

Общеизвестной проблемой свариваемости среднелегированных мартенситно-бейнитных сталей является их повышенная склонность к холодным трещинам, вследствие низкой пластичности данных материалов [1]. Распространённым в инженерной практике решением данной проблемы является использование высоколегированной проволоки аустенитного класса благодаря ее высокой деформационной способности и хорошей растворимости водорода в аустенитной кристаллической решетке [2]. Однако, такое сочетание материалов повышает риск образования горячих трещин в металле шва. Они могут наблюдаться как в виде мельчайших микронадрывов, так и видимых трещин, имеющих межкристаллитный характер [3]. Как известно, образование горячих трещин в аустенитном металле шва связано с его повышенной склонностью к формированию крупнозернистой транскристаллитной макроструктуры, особенно выраженной в многослойных швах. Кроме того, использование аустенитной проволоки при сварке высокопрочных сталей не обеспечивает механических свойств металла шва, сопоставимых с характеристиками основного металла.

На основании анализа последних исследований [4], посвященных повышению качества сварных швов и эксплуатационных свойств сварных соединений, перспективным путем решения вышеизложенной проблемы выглядит введение в зону сварки наноразмерных инокулянтов, за счет которых в процессе кристаллизации будет происходить измельчение структуры сварного шва и, тем самым, повышаться его механические свойства и технологическая прочность.

\section{Постановка задачии}

Целью данной работы является оценка влияния наноразмерных инокулянтов при сварке высокопрочных среднелегированных мартенситно-бейнитных сталей аустенитной проволокой на измельчение структуры и микротвердость металла сварного шва.

Для решения поставленной цели решались следующие задачи:

- проанализированы актуальные исследования по повышению качества сварных соединений из высокопрочных среднелегированных мартенситнобейнитных сталей, а также использованию нанотехнологий в дуговой сварке;

- изучены методы количественной металлографии, позволяющие адекватно оценить влияние нанодобавок на размерные показатели микроструктуры металла сварного шва;

- проведены экспериментальные исследования влияния наноразмерныхинокулянтов различного состава на микротвердость и морфологию аустенитного металла шва.

Экспериментальная составляющая исследований включала выполнение наплавки валиков 
с использованием наноразмерных инокулянтов разного химического состава, последующее определение микротвердости наплавленного металла и стереометрическую металлографию с измерением суммарной протяженности границ методом случайных секущих. Полученные результаты позволяют сформировать рекомендации по использованию наночастиц при сварке высокопрочных среднелегированных мартенситно-бейнитных сталей с использованием аустенитной проволоки.

\section{Использования нанотехнологий в сварке}

При сварке высокопрочных среднелегированных мартенситно-бейнитных сталей формирование в металле 3ТВ преимущественно мартенситных структур и насыщения этой области диффузионным водородом обусловливает повышенную опасность образования холодных трещин. Распространённым технологическими мерами предотвращения этих дефектов при электродуговой сварке плавящимся электродом в защитных газах является использование высоколегированных проволок аустенитного класса, из-за высокого уровня пластичности металла аустенитного шва и хорошей растворимости водорода в нем [5].

Дальнейшее совершенствование технологии сварки данных сталей стоит на пути изыскания способов сварки, позволяющих существенно повысить производительность процесса [6, 7], обеспечении качественных и равнопрочных сварных соединений.

При формировании структуры сварных швов возможности влияния на её свойства значительно более ограничены в сравнении с металлургией. Главными факторами, за счет которых можно увеличить прочность и вязкость металла шва, является легирования твердого раствора и формирование неметаллических включений определенного размера, состава и морфологии. Введение тугоплавких частичек инокулянтов в металлический расплав способствует интенсификации процесса кристаллизации и измельчению размеров образующихся зерен. Для повышения уровня механических свойств, за счет формирования мелкозернистой структуры, в зону сварки вводят наночастицы определенных оксидов или карбидов.

Одной из основных проблем использование аустенитной проволоки при сварке высокопрочных сталей является неравнопрочное сварное соединение, из-за чего необходимо искать пути повышения прочности (в т.ч. ударной вязкости) сварного шва. В данной работе изучается возможность повышения прочности сварного шва благодаря измельчению его структуры, путем введения в зону сварки наноразмерных инокулянтов различного химического состава $\left(\mathrm{Al}_{2} \mathrm{O}_{3}, \mathrm{TiO}_{2}, \mathrm{SiO}_{2}, \mathrm{TiC}\right)$. Данное пред- ложение основано на исследованиях, опубликованных последнее время, в которых показано, что введение тугоплавких соединений в виде нанокомпонентов, непосредственно в сварочную ванну, способны качественно изменять структуру и механические свойства сварного шва [4].

\section{Измерение суммарной длины линий методом случайных секущих для плоскости}

Метод случайных секущих для измерения удельной протяженности линий на плоскости был разработан и предложен в 1945 г. [8]. При выводе основной формулы этого метода не сделано никаких произвольных допущений или ограничений относительно формы линий или контуров, их расположения или ориентации на плоскости. Поэтому метод случайных секущих для плоскости является математически строгим и универсальным. Он позволяет измерять удельную протяженность линий любой системы с необходимой точностью [9]. В основе метода случайных секущих на плоскости лежит случай геометрической вероятности пересечения линии, проведенной наугад, с системой линий на плоскости, известный в теории вероятности как задача Бюффона «об игле», в нашем случае это не система линий, а фотография макрошлифа поперечного сечения наплавленного валика испытуемого образца.

На рис. 1, в качестве примера, представлена микроструктура наплавленного металла, полученная в ходе проведенных экспериментов с нанесенными для оценки её размерных показателей слу-

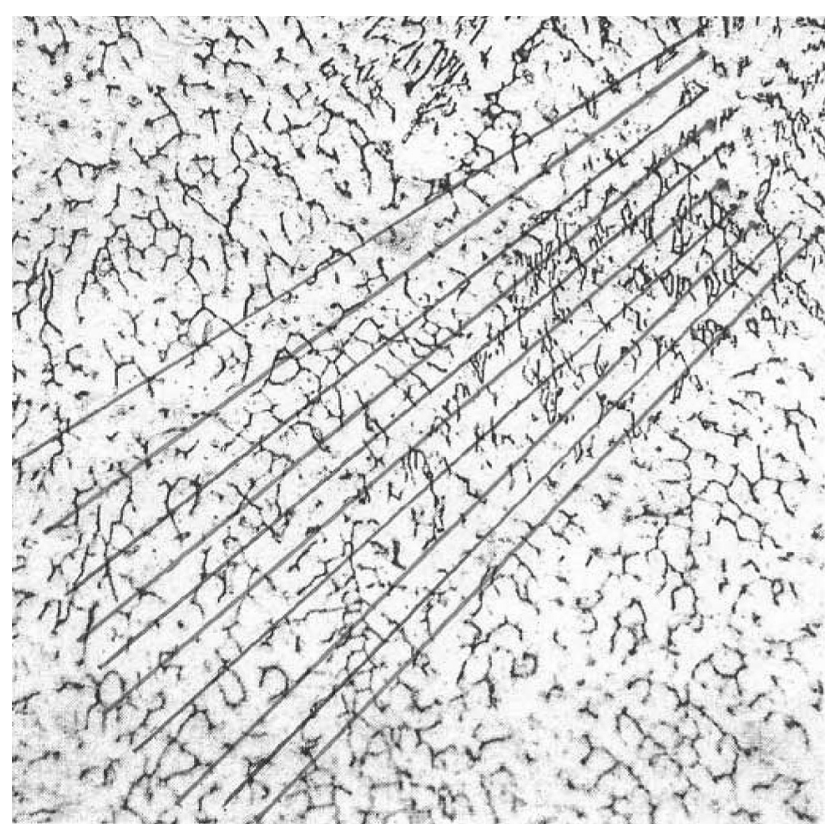

Рис. 1. Микроснимок аустенитной структуры наплавленного металла и случайные секущие, пересекающие линии границ зерен (Х320) 
Частота чисел пересечений при случайном положении секущей прямой на рис. 1

\begin{tabular}{|c|c|c|c|}
\hline Число пересечений, $m_{\mathrm{i}}$ & Число случаев, $x_{\text {i }}$ & Произведение, $m_{\mathrm{i}} x_{\mathrm{i}}$ & Частота, \% \\
\hline 10 & 2 & 20 & 1,25 \\
\hline 11 & 2 & 22 & 1,25 \\
\hline 12 & 5 & 60 & 3,125 \\
\hline 13 & 12 & 156 & 7,5 \\
\hline 14 & 10 & 140 & 6,25 \\
\hline 15 & 22 & 330 & 13,75 \\
\hline 16 & 24 & 384 & 15 \\
\hline 17 & 22 & 374 & 13,75 \\
\hline 18 & 13 & 234 & 8,125 \\
\hline 19 & 12 & 228 & 7,5 \\
\hline 20 & 17 & 340 & 10,625 \\
\hline 21 & 4 & 84 & 2,5 \\
\hline 22 & 4 & 88 & 2,5 \\
\hline 23 & 2 & 46 & 1,25 \\
\hline 24 & 4 & 96 & 2,5 \\
\hline 25 & 1 & 25 & 0,625 \\
\hline 26 & 0 & 0 & 0 \\
\hline 27 & 1 & 27 & 0,625 \\
\hline 28 & 0 & 0 & 0 \\
\hline 29 & 3 & 87 & 1,875 \\
\hline 30 & 0 & 0 & 0 \\
\hline Всего & 160 & 2741 & \\
\hline
\end{tabular}

чайными секущими. Площадь рисунка в натуре равна 0,1089 мм² (размер шлифа в натуре 0,33 на 0,33 мм), длина секущих линий 0,33 мм.

Для каждой структуры существует определенная средняя величина числа пересечений, зависящая только от суммарной протяженности линий на единице площади. Если большое число раз бросать наудачу прямую линию (рис. 1), каждый раз отмечая число пересечений прямой с линиями границ зерен $m_{\mathrm{i}}$, получим ряд значений числа пересечений. В табл. 1 приведены результаты 160 «бросаний» линии, причем линии располагались на площади рисунка случайно и в случайных направлениях. При достаточно большом общем числе «бросаний» число пересечений стремится к определенной величине. На рис. 2 приведена кривая частот числа пересечений, построенная по данным табл. 1.

Определив с требуемой точностью значение среднего числа пересечений на единице длины секущих $m$, далее находим суммарную протяжённость линий границ зерен на единице площади:

$$
\sum L=\frac{\pi}{2} \times m \times l / S
$$

где $m$ - среднее число пересечений;

$l$ - длина случайной секущей линии, мм;

$S$ - площади шлифа, мм².

Таким образом, суммарная протяженность линий границ зерен на единице площади исследуемо- 


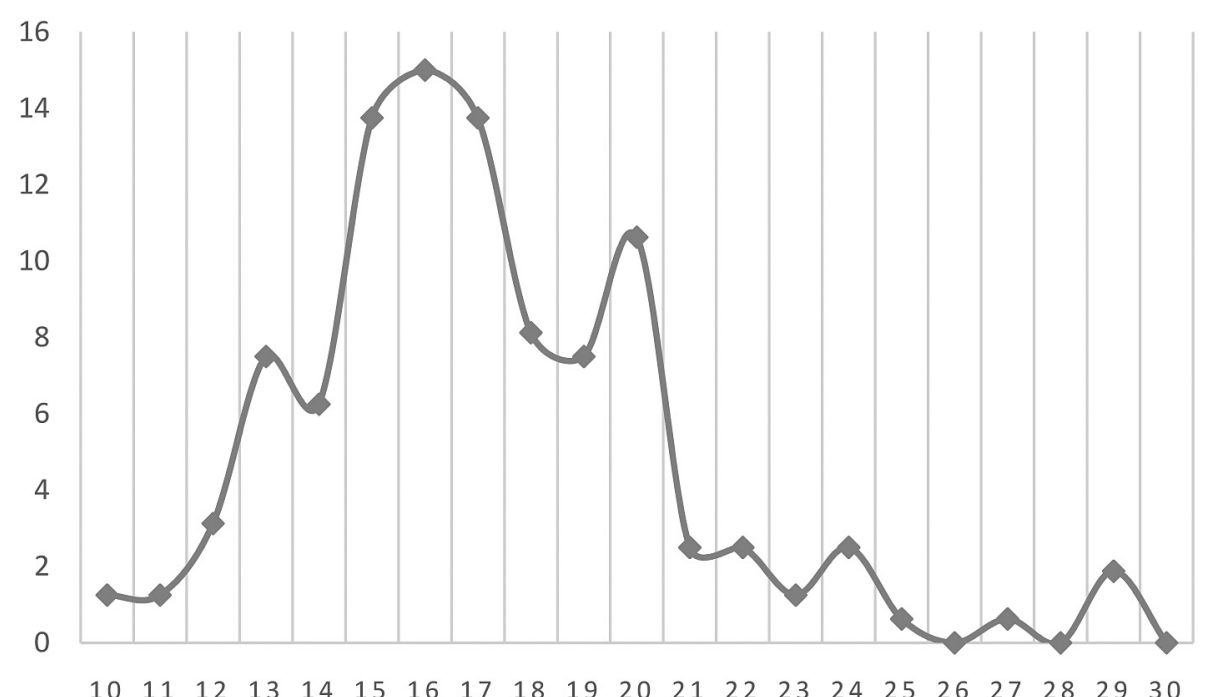

Рис. 2. Кривая частот чисел пересечений случайной секущей с линиями границ полиэдров

го образца по фотографии микроструктуры равна $51.913 \mathrm{мм} / \mathrm{Mм}^{2}$.

\section{Результаты исследований}

Экспериментальная часть исследований включала наплавку на пластину из низкоуглеродистой стали СтЗпс толщиной 10 мм валиков, сварочной проволокой ESAB OK Autrod 16.95, диаметром 1,2 мм. Сварочная проволока OK Autrod 16.95 (классификация по ДСТУ EN ISO 14343:2015 EN ISO 14343-A, G $188 \mathrm{Mn}$ ) является аналогом проволоки Св-08Х20Н9Г7Т по ГОСТ 2246-70 и широко используется для сварки легированных высокопрочных сталей. Типичный химический состав наплавленного металла при использовании данной проволоки представлен в табл. 2.

Таблица 2

Химический состав наплавленного металла [10]

\begin{tabular}{|c|c|c|c|c|c|}
\hline \multirow{2}{*}{$\begin{array}{c}\text { Марка } \\
\text { сварочной } \\
\text { проволоки }\end{array}$} & \multicolumn{4}{|c|}{ Массовая доля элементов, \% } \\
\cline { 2 - 6 } & $\mathrm{C}$ & $\mathrm{Si}$ & $\mathrm{Mn}$ & $\mathrm{Cr}$ & $\mathrm{Ni}$ \\
\hline OK Autrod 16.95 & $<0,2$ & $<1,2$ & 6,5 & 18,5 & 8,5 \\
\hline
\end{tabular}

Наплавка выполнялась механизированной сваркой в смеси газов М12 $\left(\mathrm{Ar}+2 \% \mathrm{CO}_{2}\right)$ по ДСТУ ENISO 14175. Режимы наплавки приведены в табл. 3.

В процессе исследований было использовано семь нанопорошков, содержащих смеси различной концентрации оксида титана $\mathrm{TiO}_{2}$, оксида кремния $\mathrm{SiO}_{2}$ и карбида титана $\mathrm{TiC}$ с железным порошком (табл. 4). Инокулирование в металлический рас-
Таблица 3

Режимы наплавки

\begin{tabular}{|c|c|c|c|}
\hline $\boldsymbol{I}, \mathbf{A}$ & $\boldsymbol{U}, \mathbf{B}$ & $\boldsymbol{V}_{\mathbf{~ с в}}, \mathbf{M} / \mathbf{4}$ & Расход газа, $\boldsymbol{л} / \mathbf{м и н ~}$ \\
\hline 150 & 16,8 & 11 & 12 \\
\hline
\end{tabular}

плав сварочной ванны тугоплавких дисперсоидов оксидов титана, кремния, карбида титана с грануляцией $6 . . .40$ нм осуществлялось путем их предварительного нанесения на поверхность пластины при помощи парафиновой связки.

После завершения наплавки изучались микроструктура и свойства наплавленного метала семи валиков, выполненных с использованием нанопорошковых смесей в сравнении с аустенитным наплавленным металлом, не содержащим наноинокулянтов. Для каждого случая в пяти различных областях наплавленного металла определялась микротвердость по Викерсу (HV) при нагрузке 50 гр. (табл. 5).

Для количественных металлографических исследований методом секущих микроструктура наплавленного металла фотографировалась при увеличениив 320 раз. На рис. 3 показана микроструктура испытуемых образцов, которая в дальнейшем была использования для подсчёта суммарной длины линий методом случайных секущих для плоскости.

Практической задачей данного исследования был расчет суммарной протяженности линий границ зерен на единице площади для каждого образца, который служит показателем измельчённости структуры. Таким образом, чем выше значение суммарной протяженности линий, тем больше мелких зерен образуется в процессе кристаллизации сва- 
Таблица 4

\section{Химический состав использованных нанопорошковых смесей}

\begin{tabular}{|c|c|c|c|c|c|c|c|}
\hline Смесь & № 1 & № 2 & № 3 & № 4 & № 5 & № 6 & № 7 \\
\hline $\begin{array}{c}\text { Химический } \\
\text { состав, \% }\end{array}$ & $\mathrm{TiO}_{2}-1$ & $\mathrm{TiC}-0,5$ & $\mathrm{TiC}-1$ & $\mathrm{SiO}_{2}-1$ & $\mathrm{SiO}_{2}-5$ & $\mathrm{SiO}_{2}-7$ & $\mathrm{SiO}_{2}-10$ \\
$\mathrm{Fe}-99$ & $\mathrm{Fe}-99,5$ & $\mathrm{Fe}-99$ & $\mathrm{Fe}-99$ & $\mathrm{Fe}-95$ & $\mathrm{Fe}-93$ & $\mathrm{Fe}-90$ \\
\hline
\end{tabular}

Таблица 5

Твердость наплавленного металла (HV)

\begin{tabular}{|c|c|c|c|c|c|c|}
\hline № & $\mathbf{1}$ & $\mathbf{2}$ & $\mathbf{3}$ & $\mathbf{4}$ & $\mathbf{5}$ & Средняя \\
\hline- & 232 & 201 & 210 & 210 & 201 & 210,8 \\
\hline $\mathrm{TiO}_{2}-1 \%$ & 221 & 232 & 232 & 210 & 221 & 223,2 \\
\hline $\mathrm{TiC}-0,5 \%$ & 221 & 201 & 210 & 232 & 232 & 219,2 \\
\hline $\mathrm{TiC}^{-1 \%}$ & 244 & 221 & 244 & 221 & 232 & 232,4 \\
\hline $\mathrm{SiO}_{2}-1 \%$ & 210 & 201 & 201 & 201 & 192 & 201 \\
\hline $\mathrm{SiO}_{2}-5 \%$ & 210 & 210 & 192 & 201 & 210 & 204,6 \\
\hline $\mathrm{SiO}_{2}-7 \%$ & 201 & 210 & 232 & 210 & 210 & 212,6 \\
\hline $\mathrm{SiO}_{2}-10 \%$ & 210 & 202 & 232 & 210 & 210 & 212,8 \\
\hline
\end{tabular}

Таблица 6

Характеристика наплавленного металла (HV)

\begin{tabular}{|c|c|c|c|c|c|c|c|c|}
\hline & - & $\mathrm{TiO}_{2}-1 \%$ & TiC- $-0,5 \%$ & $\mathrm{TiC}-1 \%$ & $\mathrm{SiO}_{2}-1 \%$ & $\mathrm{SiO}_{2}-5 \%$ & $\mathrm{SiO}_{2}-7 \%$ & $\mathrm{SiO}_{2}-10 \%$ \\
\hline$\sum L, \mathrm{Mм} / \mathrm{MM}^{2}$ & 81,56 & 76,26 & 94,74 & 83,31 & 66,29 & 67,96 & 96,61 & 82,83 \\
\hline $\begin{array}{c}\text { Твердость } \\
\text { по Викерсу, HV }\end{array}$ & 210,8 & 223,2 & 219,2 & 232,4 & 201 & 204,6 & 212,6 & 212,8 \\
\hline
\end{tabular}

рочной ванны. В табл. 6 отображены расчетные значения полученные методом случайных секущих для плоскости и среднее значение микротвердости данных образцов.

Результаты расчетов суммарной протяженности линии границ зерен показали, что введенные наноразмерные частицы по-разному влияют на микроструктуру и свойства наплавленного аустенитного металла. Наибольшее влияние на измельчение литой структуры шва показали наноинокулянты с составом $\mathrm{TiC}-0,5 \%$ и $\mathrm{SiO}_{2}-7 \%$.

Исследования микротвердости показали незначительное увеличение твердости металла сварного шва при введении наноинокулянтов $\mathrm{TiO}_{2}-1 \%$, $\mathrm{TiC}-0,5 \%$ и $\mathrm{TiC}-1 \%$.

\section{Выводы}

1) Методом количественной металлографии установлена принципиальная возможность измельчения аустенитной структуры металла шва путем введения в зону сварки наноразмерных добавок.

2) Установлено, что наибольшее увеличение суммарной протяженности линий границ зерен выявлено при введении в зону сварки наноразмерных инокулянтов с содержанием $\mathrm{TiC}-0,5 \%$ и $\mathrm{SiO}_{2}-7 \%$.

3) Лабораторные испытания показали, что наибольшее влияние на увеличение микротвердости металла шва наблюдается для наноинокулянтов состава $\mathrm{TiO}_{2}-1 \%$, $\mathrm{TiC}-0,5 \%$ и $\mathrm{TiC}-1 \%$, однако, 


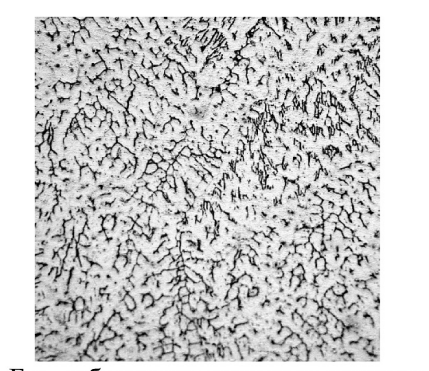

Без добавления нанокомпонентов
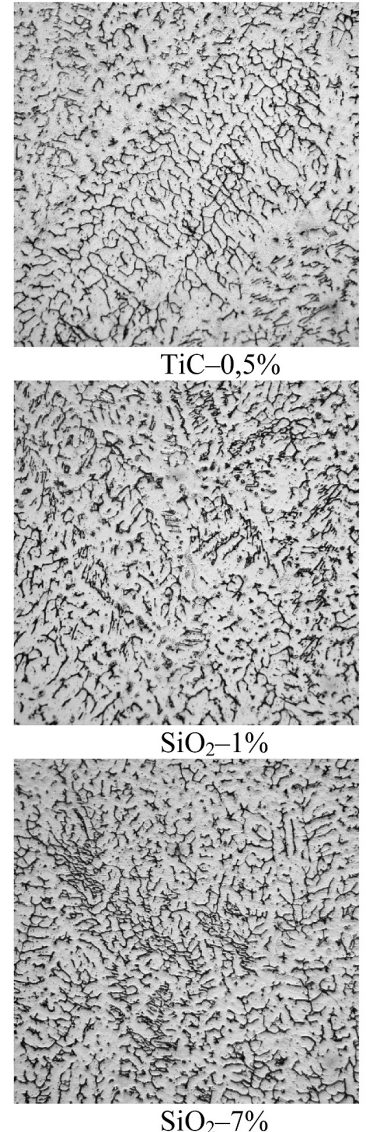

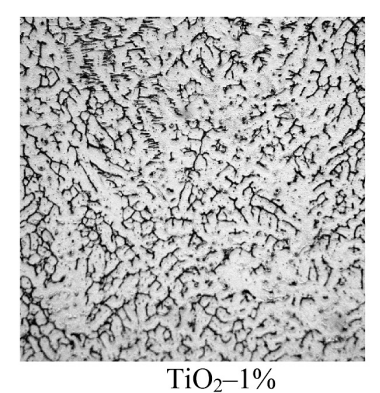

$\mathrm{TiO}_{2}-1 \%$

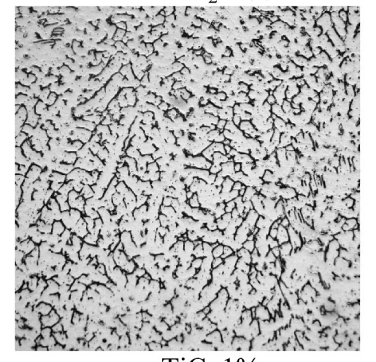

$\mathrm{TiC}-1 \%$

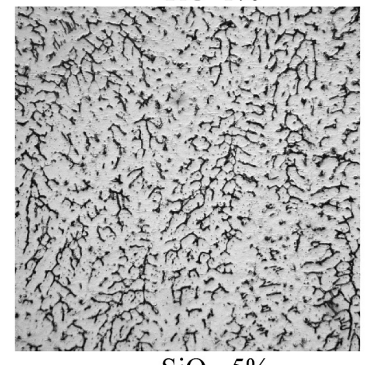

$\mathrm{SiO}_{2}-5 \%$

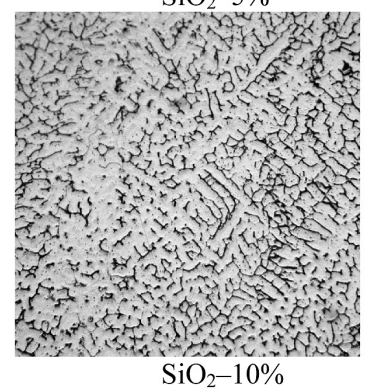

Рис. 3. Микроструктура наплавленного металла с различным добавлением наноразмерных инокулянтов (Х320)

ввиду незначительного возрастания показателей твердости, окончательный вывод о роли данных нанодобавок требует дальнейших исследований.

\section{Литература}

[1] Сварка и свариваемые материалы: В 3-х т. Т. І. Свариваемость материалов. Справ. изд./Под ред. Э. Л. Макарова - М.: Металлургия, 1991, с. 528.

[2] Дибец А. Т., Гордонный В. Г., Денисенко А. В. Стойкость аустенитного металла шва против образования горячих трещин при сварке среднелегированныйх сталей // Автоматическая сварка - 1976 № 12 - С. $6-8$.

[3] Касаткин Б. С., Козловец О. Н. Микроструктурная мартенситно-аустенитная составляющая в сварных соединениях высокопрочных низколегированных сталей // Автоматическая сварка - 1992 - № 9-10 C. $3-12$.

[4] Нанотехнології у зварюванні низьколегованих високоміцних сталей: монографія / В.В.Головко, В. Д. Кузнецов, С. К. Фомічов, П. І. Лобода. - Київ: НТУУ «КПІ» Вид-во «Політехніка», 2016. - 240 с.

[5] Сливінський О. А., Нетяга А. В. Застосування нанорозмірних інокулянтів при зварюванні високоміцних сталей мартенситно-бейнітного класу //Матеріали десятої всеукраїнської міжгалузевої науково-технічної конференції студентів, аспірантів та наукових співробітників «Зварювання та споріднені технології і процеси», - Київ: 7-9 червня 2017. C. 33.

[6] Готальский Ю. Н. Новое направление в технологии сварки закаливающихся сталей // Автоматическая сварка - 1982 - № 2 - С. 35-38. 
[7] Гончаров С. Н., Гуднев Н. З., Стеренбоген Ю. А., Гордонный В. Г., Довженко В. А. Влияние термического цикла двухдуговой сварки в $\mathrm{CO}_{2}$ на стойкость стали 20ХГСНМ против образования холодных трещин // Автоматическая сварка - 1982 - № 7 C. $14-15$.

[8] Салтыков С. А. Способ геометрического количественного анализа металлов, сплавов и т.п. объектов.
Авт. свид. № 72704, заявлено 28 мая 1945. Бюл. изобр., 1948, №10, с. 27.

[9] Стереометрическая металлография. Салтыков С. А. Изл-во «Металлургия», 1970, 3-е изд., 376 с.

[10] http://www.esab.co.uk/gb/en/products/index. $\mathrm{cfm}$ ?fuseaction $=$ home.product \& productCode $=410151$ $\& \mathrm{tab}=2$

Slyvinskyy O. A., Netyaga A. V.

National Technical University of Ukraine «Igor Sikorsky Kyiv Polytechnic Institute». Ukraine, Kiev

\section{INFLUENCE OF NANO-DIMENSIONAL INOCULATORS ON STRUCTURES AND PROPERTIES OF METAL SQUAMS IMPLEMENTED BY AUSTENITE CLASS WIRE}

The possibility of qualitative influence of nano-sized particles of various components introduced into the welding zone during electric-arc mechanized welding in a mixture of gases, on the hardness of the weld metal, and the grinding of its structure was confirmed. Based on this, the use of nano-components with the content $\mathrm{TiO}_{2}, \mathrm{SiO}_{2}$ and $\mathrm{TiC}$ for electric-arc mechanized welding in a mixture of gases of medium-alloyed martensitic-bainitic steels with high-alloy austenitic wire was proposedLaboratory, calculation and metallographic studies were carried out on the hardness and grinding of the weld metal structure, which showed the adequacy of the proposed method. [dx.doi.org/10.29010/080.6]

Keywords: mechanized welding in a mixture of gases; nano-particles; nano-powders; nano-inoculants; nano-components; nano-sized inoculants; high-strength medium-alloyed martensitic-bainite steel; austenitic wire; microhardness; metallography.

\section{References}

[1] Welding and welded materials: In 3 tons. Weldability of materials. Ref. Ed. / Ed. E. L. Makarova - M: Metallurgy, 1991, p. 528.

[2] Dibets A. T., Gordonny V. G., Denisenko A. V. Resistance of austenitic weld metal against the formation of hot cracks in the welding of medium alloy steels. // Automatic welding - 1976 - № $12-$ pp. 6-8.

[3] Kasatkin B. S., Kozlovets O. N. Microstructural martensite-austenite component in welded joints of high-strength lowalloy steels // Automatic welding - 1992 - № 9-10 - P. 3-12.

[4] Nanotechnology in low-alloyed high-viscosity steels: monograph / V. V. Golovko, V. D. Kuznetsov, S. K. Fomichov, Р. I. Loboda. - Київ: НТУУ «КПІ» View of «Політехніка», 2016. - 240 с.

[5] Slivinsky O. A., Netyaga A. V. Застосування нанорозмірних інокулянтів при зварюванні високоміцних сталей мартенситно-бейнітного класу // Masters of the tenth day of all-Ukrainian physical education, science and technology conference students, aspirants and science teachers. - Kiev: 7-9 of the year 2017. - P. 33.

[6] Gotalsky Yu. N. A New Direction in the Technology of Welding of Hardened Steels // Automatic welding - 1982 No. 2 - P. $35-38$.

[7] Goncharov S. N., Gudnev N. Z., Sterenbogen Yu. A., Gordonny V. G., Dovzhenko V. A. Influence of the thermal cycle of two-arc welding in $\mathrm{CO}_{2}$ on the resistance of 20XГCHM steel against the formation of cold cracks // Automatic welding - 1982 - № 7 - P. 14-15.

[8] Saltykov S. A. Method for geometric quantitative analysis of metals, alloys, etc. objects. Author. Svid. No. 72704, filed May 28, 1945. Bul. Image, 1948, No. 10, p. 27.

[9] Stereometric metallography. Saltykov S. A. Izlu-in «Metallurgy», 1970, 3rd ed., 376 p.

[10] http://www.esab.co.uk/gb/en/products/index.cfm?fuseaction=home.product\&productCode=410151\&tab=2 